\title{
The Effect of Critical Pedagogy-Based Instruction on Altering EFL Teachers' Viewpoints Regarding Teaching-Learning Practices and Localizing Cultural Notes
}

\author{
Abdolmajid Goljani Amirkhiz, Ahmad Moinzadeh*, Abbas Eslami-Rasekh \\ Faculty of foreign languages, University of Isfahan, 8174673441, Isfahan, Iran
}

Corresponding Author: Ahmad Moinzadeh, E-mail: moin@fgn.ui.ac.ir

\begin{tabular}{l} 
ARTICLE INFO \\
\hline Article history \\
Received: February 14, 2018 \\
Accepted: April 20, 2018 \\
Published: September 01, 2018 \\
Volume: $7 \quad$ Issue: 5 \\
Advance access: July 2018 \\
\hline
\end{tabular}

Conflicts of interest: None Funding: None

\begin{abstract}
This study aimed at inspiring EFL teachers to take a new attitude towards using teaching techniques as well as instructing cultural notes making them aware of the principles of critical pedagogy (CP) through instruction. In the same line, it tried to find out different techniques applied by teachers before and after the instruction. On the account of the dichotomy by which IRF (initiation, response and feedback) architecture is in contrast with the tenets of critical pedagogy encouraging multivocality of a classroom discourse, the teaching steps which can distinct these two architectures are still underexplored. To cover the purposes of the research, 20 EFL teachers teaching at institutes and universities were purposefully sampled to be interviewed and trained. Four sessions before and four sessions after instruction were video-recorded and taking benefit of conversation analysis methods, they were transcribed and the visible changes were dialogically discussed with the teachers using semi-structured interviews and stimulated recall sessions to find out the rationale. Adopting new techniques regarding both cultural notes and teaching techniques after instruction such as strategies in "turn taking", "latched turns", "more chances to create dialogue", "fewer teacher echo and interruption", "using L1", "educational feedback", applying referential questions", promoting self-initiation", "glocalizing cultural notes" and "less dependability on the coursebook" indicated that raising awareness among teachers considering the principles of $\mathrm{CP}$, they can change both their attitudes and abilities from transmission-based pedagogy to place-based responsive pedagogy in which learners as a whole play an active role.
\end{abstract}

Key words: Critical Pedagogy (CP), CP-based instruction, EFL teachers, stimulated recall sessions, semi-structured interviews

\section{INTRODUCTION}

One important pursuit of educational programs is to inculcate creativity and autonomy to provide a society with critical thinkers to castigate and cast ideas on whatever presented to them. Given that, a bottom up educational program in which curriculum as well as materials can be generated is required. Yet, "banking models" which is the backbone of traditional teaching is prevalent in educational settings (Freire, 1972). Naturally, the top-down educational setting contradicts the basic grounds of critical thinking both on the behalf of teachers and learners. As long as teachers are bound to teach whatever has already been designed, they cannot give birth to new ideas in teaching. Therefore, learners follow the presets in curriculum including fixed schedule, methodology, teaching techniques and learning style. Since textbooks have normative function in most educational settings, learners and specially teachers would follow the same pattern practice in teaching which is transmitting knowledge from the source of knowledge to learners. On the other side of the fence, transformative pedagogy rooted in CP takes a democratic view towards teaching and learning process making both teachers and learners benefactor providing them the opportunity to undermine the status quo (Ukpokodua, 2009). This activist pedagogy contends bilateral cooperation between teachers and learners in constructing knowledge where they are invited to question and reflect their values, norms, beliefs and learning processes. Taking the role of the teacher in didactic pedagogy the sage on the stage and in authentic pedagogy the guide on the side, then in transformative pedagogy, it would be the meddler in the middle (Cope, 2015). Therefore, this study intends to give insights to teachers through instructing the main tenets of CP as well as inviting them to reflect upon the techniques they use in their classes using stimulated recall sessions and semi-structured interviews.

Furthermore, the main principles of $\mathrm{CP}$ include reflecting on their own culture, changing the roles of teachers to meddlers and learners to critical thinkers, emancipating education from globalized traces found in textbooks and teaching practices, encouraging multivocality among learners and teachers to voice their ideas, taking an opposite view towards marginalization, encouraging praxis between action and reflection and endorsing glocalization (Yulianto, 2016). Avoid- 
ing marginalization which can be interpreted as giving voice to teachers and learners in deciding and applying what they find suitable for learning is of utmost importance (Winans, 2006). Henceforth, this is an attempt to find out whether CP principles can be conducive to adapting new insights into localizing or glocalizing cultural notes.

Considering the fact that $\mathrm{CP}$ has been reported abundant and gained significant impact on education, the number of research is few. It is evident that most research have investigated the effect of CP on a single skill or had a historical library research. Similarly, in the EFL context where glocalizing and avoiding marginalization seem to be urgent, the scarcity of research is quite evident. However, the role of teachers and their voices within the realm of $\mathrm{CP}$ in changing the steps they take as well as their views towards cultural notes and also raising their awareness through setting some CP-based instructions have been neglected.

To address this lacuna, this study is aimed at compromising CP principles, teachers' awareness, adopted techniques and their views in terms of cultural note to be used in the classrooms thorough setting up a CP-led instruction class and investigating whether it entails any changes in teachers' perspectives. The results can be contributed to EFL settings, curriculum and materials developers.

\section{LITERATURE REVIEW}

\section{Cp-Based Instruction and Teachers' Awareness}

The integral principles of CP including empowerment, emancipation from gender and written texts and avoiding marginalization in favor of critical thinking and autonomous learners are so popular that have become indispensable with current practices in language teaching. Zhang (2009) studied the effect of CP-based instruction on reading with pre-service EFL teachers and found out that the teachers have a superficial knowledge about the principles of $\mathrm{CP}$ and when they are asked questions about the application of the principles, they are unable to come up with any answers before instruction, Whereas after instruction, higher tendency towards raising critical thinking in teaching reading was reported.

Addressing the voice of the teachers, Mohammad and Malik (2014) conducted a cross-cultural qualitative study on different teachers from five different countries and found out there is little awareness among ELT teachers. Also, Yilmiz (2009) ran a study on Turkish teachers and found out the level of awareness vary among ELT teachers depending on professional seniority, educational background and the environment of the school. Regarding the teaching techniques that EFL teachers use, Rahimi and Mirzayi (2013) investigated the dominant teacher discourse structure in the classrooms using conversation analysis in Iran and found out that $87 \%$ of the discourse was based on traditional discourse structure (IRF).

\section{CP-based Instruction and Cultural Notes}

Regarding materials development, Richards (2010) and Harwood (2010) argue that there is a dire need to relate teacher-education and materials development and alerts that its importance is underestimated. Tomlinson (2003, 2005) addresses locality and emphasizes on the alignment between the thematic content and context of the materials developed with those of the local area in which they are supposed to be taught. CP which supports localization and glocalization can determine the major themes and models for materials development. A few models were represented in the literature. Rahimi, Kushki, Ansaripour and Maki (2015) based their models by drawing upon Freires' Problem Posing, Generative Themes, and Concentric Circles concepts. Additionally, the study proposed Immediacy and Comparison to be employed as tools to select and gradate the content of critical materials. Rashidi and Safari (2011) suggested a model sensitive to the particularities of the local context and to the learner's problems and concerns. It offers ways to help the learners to improve their second language skills while developing a sense of critical consciousness of issues of social structures in the world around them.

Abednia (2012) argue that instructing transformative pedagogy and its main implications in language teaching can be really promising in making a change in teachers' identity and professional improvement. Therefore due to the paucity of research carried out regarding CP-based instruction to language teachers and teach them the main applications of transformative pedagogy in contrast with the traditional IRF-based transmitted-based pedagogy in language classrooms with the main emphasis on teaching techniques and cultural notes, this study attempted to address the following research questions:

1) In what ways does CP-led awareness raising instruction affect the ways through which EFL teachers use different teaching techniques?

2) What is the dominant perspective towards teaching cultural notes among EFL teachers before and after CP-led awareness raising instruction?

\section{METHOD}

\section{Setting and Participants}

A total number of 20 EFL teachers were considered to meet the purposes of this study. Five PhD candidates teaching both at universities and institutes, five MA holders teaching at institutes, four MA students teaching at institutes and six BA holders teaching both at schools and language institutes participated in the study.

Purposive sampling was chosen. The main criteria were various educational statuses, age range between 30 and 50, teaching experience at least for five years and willingness to participate in the study. It is necessary to mention that gender was not considered as a significant factor.

The students whose classes were observed had all an upper-intermediate level proficiency in English. The classes were all segregated.

The classes held by the participants at institutes were observed and video-recorded. To confirm the reliability, 4 sessions before and 4 sessions after the instruction were monitored. Of course, the consent of participants 
and institutes' managers were taken. Each recording took 30 minutes and were narrowly transcribed (see appendix for transcription key). Since the necessary data was gained to explore and delve into the research questions, the recordings were sampled and those which could not add any new information to the data were discarded. Therefore a total of 12 transcription before instruction and 15 transcriptions after the instruction were used. The purpose of recording, transcribing and observing the classes was to find obtruding and facilitating factors used for encouraging or barging multivocality.

Furthermore, participants went through semi-structured interviews (SSI) and stimulated recall sessions (SRS) to ask them to explain their moves in the classroom. In SRS, the teachers are invited to watch the videos filmed and asked to explain about the teaching steps they took to assess the rationale behind each measure.

Afterwards, the teachers took part in a 15-session CP-led instruction class in which the main tenets of critical pedagogy regarding teacher and learner roles, the role of materials and textbooks, steps of teaching, transformative pedagogy, teaching methods, teachers' authority, types of dialogues, standard English and the nature of ELT were taught. After four weeks, the classes of the same teachers were observed, recorded and randomly transcribed. To analyze the transcripts, conversation analysis (CA) methods were applied.

The CP-led classes implemented in this study drew upon Abednia (2009) study with some modifications which itself is based on Crawford (1978) research. The approach is to encourage critical thinking and creative action using problem-posing technique. The content of the instruction was mainly drawn on the video-recordings taken from the classes and the main technique was problem posing so that every teaching step taken by the teachers which could be discussed and challenged was paused and the participants were encouraged to explain about the rationale behind their techniques and then its replacement within CP was suggested and discussed.

Furthermore, to trace the realization of techniques used in the classroom by teachers, the framework suggested by Rashidi and Safari (2011) was used. After discussing the principles, 20 minutes of the recorded activities was played and teachers were invited to check the items in the checklist and after there was a cooperative negotiation among the members of the class to check the features which hampered or assisted the principles in the checklist. For the upcoming session, the participant teachers were asked to transcribe 20 minutes of their classroom activities, reflect upon different parts and write how they can align their strategies in using $\mathrm{CP}$-informed materials.

\section{RESULTS AND DISCUSSION}

\section{Before Instruction: Teaching Techniques}

The dominant setting observed in the classes is a coursebound teacher-controlled discourse in which the steps and pace of teaching are highly affected by the coursebooks. The interaction is mainly revolved around the topics and pictures in the coursebooks and teachers mainly interrupt the flow of the conversation to regain the floor and determine who should answer or follow the discussion which is evident in traditional latched or overlapped turns.

\section{Extract 1}

1 T: Fine! Threats to culture. You know, the dangers uh. for a culture, what they might be? Ok, Samaneh, do you have any ideas?

2 S1: Um, I should say about my culture or other cultures?!

3 T: Ok, feel free. It doesn't matter which you wanna talk about, just tell the most important things that come to your mind.

4 S2: May I say?

5 T: Yes.

6 S2: I think new ways of communication uh can be dangerous for example Internet

7 T: Aha, what do you mean?

8 S2: Actually, they show different programs

9 T: You are right, then children and others can watch uh [pause], not suitable programs which umm display the culture of other countries for example different lifestyles, Iranian lifestyle, Islamic life style, Western lifestyle, What is your idea Farnaz?

10 S3: Umm, yes. That's a difficult question [Pause] they try to show different parts of umm their life

11 S4: For example wearing different clothes

12 S2: religious things

13 T: others ...

14 S5: relationships between boys and girls

15 T: Fine, so you see there are many things that can put the culture into danger, but there is this question whether globalization is good or not?

16 S3: Sorry what?!

17 T: You will find out, now look at the book and read the text ...

As seen, the teacher starts the cycle of interaction choosing the topic of the reading and asks one particular student a general question. It seems that the student (S1, turn 2) is confused and tries to make the situation less ambiguous. In the next turn, the teacher again gives even a broader explanation rather than narrowing down the question. According to Beach and Metzger (1997) when a participant can not understand a part of the conversation or remain confused, it should be interactionally worked out. In the next turn, another student volunteers to answer the question to which teacher consents. It is surprising that student 1 does not participate in the conversation again. In turn 9, the teacher gains the floor and poses another question. In the next turns, students try to answer the question collectively. In the $15^{\text {th }}$ turn, the teacher jumps to another question which is about a rather unfamiliar term "globalization" to which learners reacted confusingly and at the end learners are referred to the book for further study. The critical point is that learners must be able to initiate and negotiate meaning in the class to criticize and question the status quo, but as it is seen the teacher repeatedly grosses over and changes the recipients which makes other 
learners unwilling to communicate and hence their voices and ideas are marginalized, not attended or even ignored. The stems which should prompt learners to speak are taken from the coursebook which are not enough to stimulate learners to talk, as a result, the teacher functions as the addressee and learners are often unable to provide a complete answer. The rather lecture-like explanation given by teachers shows transmission-based context in which teachers act as the source of knowledge who must impart knowledge to make learners able to pick up the correct form of language. In this case, teachers repeat specific structures deliberately so learners can naturally pick them. Encouraging learners to criticize the important issue of the culture is obstructed by long explanation given by the teacher (turn 2.9.15) and limited-wait time (turn 4 and 7). When the teachers are asked about the long explanation, they assert that the purpose is to carry out a warm up activity just to make learners familiar with the upcoming text and they do not intend to elicit any clear responses from the learners (SRS). They are also asked why they changed the recipients frequently to which they respond that they are just looking for one student who can leave comments on the posed question and further discussion is not sought (SII). By the same token, it is inquired why there is no waiting time given to the learners which the frequent answer is that they do not consider this during teaching at all (SII). The reason for not having dialogical problem solving negotiation was asked which most of the teachers surprisingly said that they were simply unaware and not instructed before (SII). In fact, posing difficult questions, changing the recipients to answer the question and not giving enough thinking time obstructed the learners attempt to enunciate their voices which consequently made the interaction close down. It can be conceived as the exercise of power. Teachers are almost of the opinion that giving the opportunity to learners to express their ideas freely can waste the time of the class and bring about cluttered discussion (SRS), so they interrupt learners to manage the time in the class (SII). It can impede "the future-action environment" on the behalf of the addressee (Locehr \& Bousfield, 2008).

Furthermore, the dominant approach among teachers is transmission-based which limits posing problems to raise discussion in dialogical form to make the cycle of action and reaction. Quite the contrary to what $\mathrm{CP}$ requires regarding the shadow role that teachers must take, considerable instances of latched turns are observed in the classes where learners are not given enough time to think, share and incubate a lengthy persuasive response to the prompt which give the feeling that learners were just fed the lines (Walsh, 2002).

\section{Before Instruction: The View Towards Cultural Notes}

Place responsive pedagogy seeks to draw the commonalities of local culture and target culture into the locus of attention, yet most stream materials are written with a global perspective oriented more towards British and American culture leaving a bleak picture of outer circle countries. Yet, EFL teachers following the transmission-based approach make no effort in spicing the classroom topics with local and familiar topics. The following excerpt is taken from one of the observed classes in which the topic of the discussion is wedding traditions and practices around the world. But a closer look reveals that the attempt is to boost learners' cultural awareness associated with inner-circle countries. The teacher gives some explanation on the topic and distinguishes some terms such as "tradition", "practice", "ceremony" and "celebration" for students. Then he instructs learners to take a look at the photos and explain about what they see. Then, he asks learners to read the text and answer the questions. Eventually, the cycle of teaching finishes with a listening track played to which learners are supposed to listen and answer the questions. The track is mainly about wedding tradition in Britain and Korea. What is evident during observation is the lack of waiting time for learners to express their ideas, teaching the cultural notes rather than discussing and criticizing them which are devoid of any dialogue about the local culture.

\section{Extract 2}

1: T: Well, wedding around the world. One of the main important decisions that a person makes is getting married. It has different forms in different countries. Do you know ummm what wedding is?

2: S1: It's a celebration that two young people get married and umm start a new life.

3: T: Very well, Take a look at the pictures, WHAT do you see in the PICTURES?

4: $[0.5]$

5: T: Any volunteers??

6: S2: I can see someone ummm [0.2] what is he doing?

7 T: throwing ...

8 S2: yeah, throwing rice

9: T: Yeah, do you know why ((students take a look at each other for some moments))

10: $\mathrm{T}$ : Ok, this is a tradition in the USA that is for showing best wishes and best luck ((the teacher write the important words on the wall)) and also PROSPERITY ((he is writing it on the paper)). But actually they don't do it anymore because birds eat them and die after that. Ok, what else?

11: S3: Well, I see some flowers, I think she wants to throw them.

12: T: BOUQEUT!!! ((the teacher is writing the word on the board)) yeah, actually the GROOM is TOSSING the bunch of flower back so everyone who gets it first will marry soon. Very well, what else you see in the pictures?

13: S4: [0.4] there are some boys that are travelling ....

14: S5: (raised his hand) I know the days before wedding, sorry, what داماد is in English?

15: T: groom

16: S5: yeah, groom and his friends go to travel.

17: very well, now take look at the texts and ....

The teacher starts the class introducing the topic of the lesson. Then he follows up the discussion asking learners about wedding to check what they know about it. The reason is explained that learners may know some words related to the wedding and teachers can elicit them (SRS). As it can 
be seen, the focus is on eliciting words which is categorized as feedback on the language (Turn 1,2). It can show that the main focus of the teacher in the first turns is not raising cultural awareness and instead he tries to elicit related vocabularies (SSI before the CPLI). The whole phase of the interaction revolves around the coursebook and the pictures (turns 3. 10, 12, 17). It is asserted that teachers are cautious and at the same time worried about the possible questions and new words that learners may ask if they open up discussion about other cultures specially the local one (SRS, SII). One glaring obstruction in the excerpt is the lack of waiting time, if not any. It is obvious that the teacher does not look for ideas and tapping the cultural knowledge, yet he seeks a prompt answer "to avoid any further discussion" (SRS). Another tangible point is the attempt made by the teacher to gain the floor giving long lecture-like explanation about each picture turns $(10,12)$. This is explained that when learners do not have much to say because they are not aware of the cultural tradition and also avoiding the awkward silence in the class, this is necessary to provide them with information (SII).

The extract truly reported that transmission pedagogy is the backbone of the teacher-fronted discourse structure of the class in which learners are receivers and teacher is the distributer of the knowledge. The architecture of the class is maintained by addressing learners' names, being bookbound, limited waiting-time, long explanations, overextended teacher turns, not using pair and group work activities, and avoiding to talk about cultural notes about other countries as well as the local one. The statements such as "there was not enough time to ask learners bring their materials to the class" (SII), "the coursebook is the main source to be covered in the class" (SII), "asking learners questions about the local issues can deviate learners from the coursebook" (SII) show that teachers are bound to coursebooks and their main focus was finishing what they were supposed to teach.

\section{After Instruction: Teaching Techniques}

Having instructed the teachers and providing them with CP-led teaching techniques, the classes were observed and reported. In this excerpt, the class is working on a conversation regarding wedding ceremony. The most noticeable and striking feature is the pace of teaching which is slower and the teacher provides learners with enough waiting time to ponder and discuss the problem posed in groups and after that learners are voluntarily assigned to answer the questions. In other words, the teacher takes less control on the flow of the conversation as well as turn taking which obviously can permit the voice of learners to be heard. Learners are more invigorated to express their ideas and criticize the status quo. As it is seen, after posing the problem, the teacher takes a backseat and lets learners negotiate more elaborately in groups. In the same line, the number of interrupted and latched turns clearly shows that learners are more willing and ready to express their ideas and also try to compete to take the floor. In the following extract, the teacher has written four questions on the board before asking learners to discuss the questions in their groups of three which have been arranged according to the learners' attitude on traditional and modern marriages. The learners have been given 4 minutes to discuss the questions before they are asked to answer the questions voluntarily. The important point is that the teacher has designed questions including both local and global issues aiming at stimulating learners to discuss.

\section{Extract 3}

1. T: Well, the first question, should EVERYone gets married at a specific age? (Waiting for some short seconds until someone starts talking)

2. S1: As we talked, there is no right age to decide exactly but in Iran it is usually above 25 years old. But it depends to

3. T: On

4. S1: yes, on uhh different things

5. T: for EXAMPLE

6. S2 (The same group) Yes, money is important too. Maybe you are 20 years old but you have money so you can marry

7. T: get married, very good, OK, so, what if you don't have money, it means you shouldn't get married or how much money is enough?

8. S2: ((Clearing his throat)) umm, well, ((he starts to laugh)) maybe

9. S3: You should be able to have a normal life, if you live without money, it can be very hard.

10. T: Well, anybody else ...

11. S4 (another group): I guess personality is important as well, a person should be, you know, old enough to understand everything

12. T: You mean mature enough

13. S5: Yes, can you write it please?

14. S6 (the same group) but I think all of them are important, but if a man and a woman want to get married, they can work after that to make everything, if they have everything from the first, what they should do after marriage and ummm not all the people have this situation

15. (someone else raised his hand) T: Yes, Ali

16. S7 (Another group) we think age is not important, when two people love each other, they should get married

17. (Some students raise their hands suddenly and teacher chooses the one who didn't speak)

18. S8: But love is short and after a short time they will see the reality so if two people think about everything, it is vرتشم ى مطقن very better, they should have

19. T: (The teacher notes something down) Things in common (The teacher writes it down)

The topic is really challenging and inviting to make leaners voice their thoughts. In the similar line, the teacher has asked learners to study about the topic and bring a piece of paper to the class. These two techniques can elicit learners' ideas to be voiced and raise the rate of student talk in the class. Student 1 voluntarily takes the floor and expresses the opinion discussed in the group and produce a sentence-length response. The teacher does not let learners give a general response to the question by asking "for example" (turn 5) intending to elicit learners more output. Actually us- 
ing silence time and asking for clarification techniques, the teacher tries to make learners elongate their terse responses which make others start to talk (turn 6). Whatever techniques which can spur the conversation among learners rather than leaners with teachers can help the voices to be heard more, in so doing, the teacher bounces back a question to the learner (turn 7) which encourages other learners to talk and express their ideas. To consider the whole picture in this extract, the teacher chooses to keep being silent to reduce teacher talk time which of course sparks up motivation for learners to talk to get rid of the awkward silence in the class; it makes learners aware that they are responsible to contribute more in the classroom and teacher takes a backseat role (Turns 10, 12, 17 and 19). During the conversation, however, the teacher nodes down, jots down points and shows facial expressions (McCarthy, 2003). For example in turn 8, the learner is clearing his throat trying to voice his idea but the teacher does not intervene and waits for other learners to react which finally leads to the next turn and a long answer.

At the end of the discussion, the teacher writes the mistakes he has noticed on the board and asks learners to rectify them. This type of delayed feedback is given indirectly since "learners may find their confidence in danger and get reluctant to express their ideas anymore if they are given immediate feedback" (SRS).

In turn 18 , one of the students uses code-switching technique to convey his meaning and the teacher does not react negatively and accepts it as a natural flow in the conversation.

As it is plainly seen, the new techniques taken by the teacher inspired by the CP-led instruction has reduced not only teacher talk time to a great extent but also the number of turns he takes which eventually leads to more negotiation and turns among students making dialogue even multilogue, occasionally. Naturally, the teacher is not the only discourse maker in the class and instead learners play a more highlighted role in arranging the discourse structure of the classroom. More think time and scaffolding make learners more willing to communicate and voice their opinions. Giving graduated feedback removes the danger of making reticent learners (Xie, 2010). In the same line, replacing discouraging words with encouraging remarks can charge learners with more enthusiasm to speak. Using more referential questions instead of display questions can propel the negotiation along as well. All in all, resting the topic of the conversation in learners' lives has an awarding effect on learners' motivation to create and elongate the discourse. In other words, a familiar context leads to multivocality in the classroom setting.

\section{After Instructional Sessions: The view towards cultural notes}

In the following excerpt, the topic of the discussion is cultural manners and norms which are introduced as "World cultures". The unit is about traditions and things people would miss about home if they lived abroad. There are some explanations about South Korea, Peru, Japan and Australia about their traditions including food, handicrafts, sculptures and music performance. The teacher had previously asked learners to reflect upon the things they would miss and how they would deal with them about their home country, Also learners were asked to criticize the norms and traditions in their home country as well as the ones proposed in the textbook. What is mainly evident in the class is that there is a shift from globalization to glocalization and finally to localization and learners are encouraged to discuss and criticize. The process of reflection and action using generative topics to encourage discussion is emphasized. The teacher tries to remain silent and asks for clarification to encourage dialogue and even multilogue in the classroom. He also tries to give content feedback and delayed feedback.

\section{Extract 4}

1. T: Today we are going to talk about different traditions around the world and Iran. What would you miss about your home country if you lived in another country? (Students are given time to talk about the question in groups for 3 minutes and then students are asked to answer voluntarily)

2. S1: The first and the most important thing is family. The only thing that you cannot have again is family ...

3. T: What do you mean?

4. S1: I mean you can have friends, job, house but family is not possible.

5. S2: (Just interrupts) ok, you can take them with yourself (the students laugh quietly)

6. T: (The teacher looks at S2 with a smile on his face trying to persuade $\mathrm{S} 2$ to talk more)

7. S2: I am kidding, yes, Amir is right. But I think when you want to leave the country, you must be very

8. T: (the teacher stands up and writes "decisive" on the board and nods)

9. S2: Thank you, but you can contact them with social networks such as "IMO" or "What's up" (some students raise their hands and teacher chooses one of them)

10. S3: But I think after a while, they get habit (the teacher gently says " are getting used to") to this situation. I would miss my friends too. Here you have some old friends from school that you know them for a long time and you are very close but in another country you should find new friends.

11. T: Ok, family and friends, it is ok, but remember we are talking about traditions such as clothes, food, music ...

12. S4: (After a short silence, S4 raises his hand) May I talk?

13. T: (The teacher nods)

14. S4: I heard it is difficult to find delicious foods in other countries and they do not match our (a silence which suggests that the S4 looks for the correct word)

15. $\mathrm{T}$ : taste

16. S4: yeah, thanks. So I think I will miss them

17. T: (without breathing a word, the teacher looks at others having a smile on his face expecting answers)

18. S5: But I think when you are in another country, there are many other things to make you amused and you will forget the traditions in your country. New foods, people, language, customs and everything is new and interesting so I guess I will miss nothing. 
19. S6: Really! Maybe! But I think I will miss Norouz, Sizdah be dar, different eves not just for the days but because of the memories I have.

20. S7: and I want to say that if I stay for a long time, in the first years I won't miss anything but after a while I will feel homesick.

21. T: Thank you everybody now I want you ... (The teacher changes the topic of the discussion)

The teacher initiates the topic in the class and provides learners with some time to reflect, refresh and discuss the topic in groups taking this into account that learners were supposed to consider the topic at home. This can assist not only the teacher to evaluate and assess how much learners are ready to participate but also the learners can retrieve the information, collect their ideas to participate and hear other learners to become aware of new ideas. This can help the teacher to understand the present level of the learners and then departure the rest of the class based on that (Shor, 1992). Having discussed the question for three minutes, S1 takes a self-initiated turn, voluntarily breaks the silence and takes the floor with short response which is followed by a question on the part of the teacher to elongate and clarify the response which leads to turn 5 taken by S2 who leaves a funny remark on $\mathrm{S} 1$ followed by a gaze filled with silence and smile on the part of the teacher to make S2 clarify more resulting in a longer answer. To leave the discussion uninterrupted, when S2 cannot say one word in English, he uses a word in mother tongue to which the teacher does not react negatively and instead writes the word on the board. As S2 is ending his turn, other students volunteer to participate which shows the effect of undirected elicitation through which the teacher remains silent and does not intervene the negotiation process. S3 in the tenth turn provides a fairly long discourse while other learners as well as teachers listen carefully. In the next turn, the teacher directs learners again to other aspects of traditions and avoids distraction of the main topic. In the next turn, learners discuss about the point to which the teacher refers to without being interrupted. The main purpose is to make learners talk about the local issues around them and that's why the learners could easily talk lengthily about the topics which they have enough background (SRS). Furthermore, when learners understand that the teacher has chosen a silent role, they do not rely on the source anymore and try to overcome with the awkward silence in the class which can lower the time of teacher talk and add it to the time of the learners talk (SRS). The only beneficial backchannel on the part of the teacher is the smile on the face and directed gaze at the learners to elicit answers which encouraged learners to voice their ideas more (SII). One important point that changes dialogue into multilogue in the classroom and gives a backseat role to the teacher is implementing the whole discussion around the localized norms. It seems due to more active content and even formal schemata, learners are more willing to communicate (SII). Another point of discussion is that the whole management of the class by the teacher creates enough condition for "pushed output" (Swain, 2000). Learners are mainly engaged in the process of expanding discourse rather than passing the responsibility; besides, it stimulates learners in the process of creating dialogue (SRS).

\section{DISCUSSION}

The results obtained from the study clearly reveal that the teachers participated in the CP-led instruction courses could successfully manage the moves in their classroom management so that silenced and marginalized learners were made to participate in the classroom discussion leading to multivocality, dialogues and even multilogues. This change in management can be explained in some grounds. First, the discussion should be made within the course of CP-led instruction and the total change in classroom discourse structure. Initially the teachers had considered learners as passive recipients of knowledge; as a result, they did not expect the learners to contribute. In the other words, they could not successfully employ the whole faculties of students including thought, feeling, body and creativity. Furthermore, the whole class discussion was divorced from the real context of living for learners and incompatible with their content and formal schemata. However, getting cognizant of the notion that learners should be considered as whole as well as taking account of the familiar topics, they managed to provide more opportunities for expressing voices in the class. This makes them more confident in future to venture on voicing their opinions and taking risks (SRS).

Employing self-observation and transcribing the classes, teachers noticed the obstructive and consecutives moves for and against instigating multivocality in the classroom. Self-monitoring the moves helped teachers to raise their awareness towards better classroom management in terms of eliciting speech from learners, furthermore, negotiating the moves with an educator and reflecting upon the moves had a significant change on the attitude as well.

Dialogic reflection can assist teachers to have teaching output on the basis of the teaching input they have observed and also discuss the teaching moves to find a rationale behind them. In the same vain, according to Chick (2015) this reflection can lead teachers to reach a deeper understanding into the complex and multilayered nature of the practices in language teaching in order to take new actions and plausible alternatives. In the same line, the persuasive nature of the dialogic discussion can co-construct a mutual understanding between the teacher and educator.

Further to the point, the instruction, video-recording, self-monitoring and reflection can all co-create a mental area within which education and teaching can act more efficiently (Wedell \& Malderez, 2013). This area is referred to as the Zone of Proximal Teacher Development (ZPTD) (Warford, 2011), which can be an ideal in realizing the next move for teachers.

Results can also be interpreted in terms of the praxis used in the study by which the teachers took actions in the class followed by a reflection session, after that teachers went through instructional sessions and then were asked to run their classes according to the co-constructed moves of teaching, then they had a dialogic session to reflect upon their teaching. This action, reflection, instruction, action and reaction cycle (i.e., praxis) can account for the changes after $\mathrm{CP}$-led instructional sessions.

Therefore, the answer to the first research question is affirmative in the sense that the participating teachers before instruction used to apply short wait time, bookbound 
practices, self-directed discussions, obtrusive interruptions, ignoring or discouraging learners' self-initiated turns and discouraging the use of L1. However, after instruction, it was quite evident that the techniques were changed considerably in terms of more delayed responses, more wait time, more think time, more patience, providing educative feedback, encouraging the use of $\mathrm{L} 1$, resorting to referential questions and inspiring self-initiated turns in the classroom and among the learners.

In the same line, the answer to the second question is affirmative either since the teachers tried to localize and glocolize the topics in the coursebook which eventually led to more negotiation and talk.

\section{CONCLUSION}

This study was an attempt to impart the tenets of critical pedagogy to teachers through instruction to find out any possible changes in the teaching techniques they apply and the strategies they adopt to teach cultural notes before and after instruction. In tandem with instruction, the participating teachers were invited to reflect upon the move they take using stimulated recall sessions and semi-structured interviews. The results clearly depicted that critical pedagogy can have a tremendous effect on transformative pedagogy among Iranian teachers to change their attitudes in terms of teaching techniques and cultural notes. It also vividly shows that making teachers aware of the tenets of critical pedagogy can change the way that they consider learners, culture and teaching steps. Prior to instruction, the "culture of silence" (Freire, 1972) was maintained among learners and the teacher would manage all the steps in the class, nonetheless, the CP-led instruction changed the view among teachers to consider learners as active participants of knowledge rather than pre-packed recipients of information. Indeed, using reflection and educational dialogue, the participating teachers practiced relinquishing their authorities among learners and employing different moves to instigate multivocality among learners. Furthermore, prior to the instruction, the whole discourse around cultural notes were wrapped in textbooks which are advertising the inner circle culture, however, after instruction, the attitude changed towards using learners' voice to talk about the local culture and criticize the global one.

In the light of CA methods, this study made an attempt to find out obstructive and constructive moves to promote teaching techniques as well as paying attention to cultural notes in language classrooms. Therefore, it is suggested that teachers and teacher educators pay special attention to the tenets of CP and apply them in their classes to avoid the culture of silence, encourage the spirit of voicing ideas, terminate the unjust status quo of the asymmetrical role in language classrooms and promote local culture taking advantage of glocalizing and localizing the topics in coursebooks.

\section{REFERENCES}

Abednia, A. (2009). Transformative second language teacher development: A tentative proposal. In P. Wachob (Ed.), Power in the EFL classroom: Critical pedagogy in the
Middle East (pp. 263-282). Newcastle-upon-Tyne, England: Cambridge Scholars Publishing.

Abednia, A. (2012). Teachers' professional identity: Contributions of a critical EFL teacher education course in Iran. Teaching and Teacher Education, 28(5), 706-717.

Beach, W. A., \& Metzger, T. R. (1997). Claiming insufficient knowledge. Human Communications Research, 23 (2), 562-588.

Chick, M. (2015). The education of language teachers: instruction or conversation? ELT Journal, 69(3), 297-307.

Cope, B. (2015). Introduction to three pedagogical paradigms [CG Scholar Update]. Retrieved from https://cgscholar.com/community/community_profiles/eps-431new-learning-2015/community_updates/23137

Crawford, L. M. (1978). Paulo Freire's philosophy: derivation of curricular principles and their application to second language curriculum design. PhD dissertation, University of Minnesota.

Critical Pedagogy in Language Teaching (PDF Download Available). Available from: https://www.researchgate. net/publication/277707707_Critical_Pedagogy_in_ Language_Teaching [accessed May 01 2018].

Freire, P. (1972). Pedagogy of the oppressed. New York, NY: Penguin Books.

Harwood, N. (2010). English Language Teaching Materials. Cambridge University press.

Locher, M., \& Bousfield, D. (2008). Impoliteness and power in language. In D. Bousfield \& M. Locher (Eds.), Impoliteness in language, power and social processes (pp. 1-17). Berlin, Germany: Mouton de Gruyter.

McCarthy, M. J. (2003). Talking back: "Small” interactional response tokens in everyday conversation. Research on Language in Social Interaction, 36 (1), 33-63.

Mohamed, A. A., \& Malik, A. (2014). ELT Teachers' Awareness of Critical Pedagogy: A Cross-Cultural Study. Journal of ELT and Applied Linguistics, 2(3), 13-27.

Rahimi Domakani, M., \& Mirzaei, A. (2013). Exploring dialogism and multivocality in L2 classroom-discourse architecture in Iran. Journal of Issues in Language Teaching, 2(1), 83-100.

Rahimi, A., Kushki, A., Ansaripour, E., \& Maki, A. (2015). Critical pedagogy and materials development: Content selection and gradation. Educational Policy Analysis and Strategic Research, 10(1), 24-38

Rashidi, N. \& Safari, F. (2011). A Model for EFL Materials Development within the Framework of Critical Pedagogy (CP). English Language Teaching, 4(1), 250-259.

Richards, J. C. (2010). Series editor's preface. In N. Harwood (Ed.), English language teaching materials: theory and practice. Cambridge: Cambridge University Press.

Shor, I. (1992). Empowering education: Critical teaching for social change. Chicago, IL: University of Chicago Press.

Tomlinson, B. (2003). Humanizing the course book. In B. Tomlinson (Ed.), Developing materials for language teaching (pp. 162-173). London: Continuum.

Tomlinson, B. (2005). The Future for ELT Material in Asia. Electronic Journal of Foreign Language Journal, 2(2), 5-13. 
Ukpokodu, O. (2009). The practice of transformative pedagogy. Journal of Excellence in College Teaching, 20(2), 43-67.

Yilmaz, K. (2009). Elementary school teachers' views about the critical pedagogy. The Asia-Pacifc Education Researcher, 18(1), 139-149.

Walsh, S. (2002). Construction or obstruction: Teacher talk and learner involvement in the EFL classroom. Language Teaching Research, 6(1), 3-23.

Warford, M. K. (2011). The zone of proximal teacher development. Teaching and Teacher Education, 27(2), 252-258

Wedell, M., \& Malderez, A. (2013). Understanding language classroom contexts: The starting point for change. London, England: Bloomsbury
Winans, A. E. (2006). Queering pedagogy in the English classroom: Engaging with the places where thinking stops. Pedagogy: Critical Approaches to Teaching Literature, Language, Composition, and Culture, 6(1), 103-122.

Xie, X. Y. (2010). Why are students quiet? Looking at the Chinese context and beyond. ELT Journal, 64(1), 10-20.

Yulianto, S. W. (2016). Critical pedagogy principles in teaching EFL reading. Journal of English education, 4 (1), 25-38.

Zhang, L. J. (2009). Teaching critical reading to in-service EFL teachers in Singapore. TESOL TEIS Newsletter, 24(1), 1-10

\section{APPENDIX}

Transcription key (Adopted from Hutchby and Wooffitt, 2008)

? Question mark expresses slight rising intonation (and sometimes questions)

. A dot shows slight falling intonation

: Colon (s) means prolonging of sound and the number of colons says the length of the extension

$\uparrow \downarrow U$ u and down arrows indicate that there is sharply rising or falling intonation and locate before the syllable in which the change in intonation occurs

[] Overlapping in speech

(.) Micro-pause (0.2 second or less)

(0.4) Numbers in parentheses demonstrate length of silence in tenths of a second

((nod)) Double parentheses demonstrate non-speech activity or transcriptionist comment

$1 / 4$ Equal sign shows continuing speech with no break in between

$1 / 4$ Equal sign shows continuing speech with no break in between 